\title{
An Overview of Ethiopian Education System, Curriculum, Curriculum Development Processes and Its Historical Trends and Patterns: A Review
}

\author{
Bezabih Wondimu, $\mathrm{PhD}$ \\ Department of Educational Planning and Management, College of Education and Behavioral Studies, Madda \\ Walabu University; Bale-Robe/ Ethiopia
}

\begin{abstract}
Ethiopia is one of the country located in horn of Africa which has more than 100 million people today. Ethiopia has long history in all aspects like education, cultures, norms, values, religious, farming style and so forth. To understand modern Ethiopia's needs and the context of educational reform, one must understand the history of education in the country. Thus, the objective of this review is to explore an overview of Ethiopian education system with emphasis on the curriculum development in different periods on its historical trends and patterns. The main sources for this review were literatures and personal experiences of the author. Qualitative method, more specifically historical research was employed. The understanding and practices of curriculum development i.e. curriculum planning, tryout, implementation and evaluation has varied throughout the history of Ethiopian education. The review work come up with conclusions that the education system of Ethiopia in general and the curriculum in particular has undergone several phases of development with subsequent foreign influence. In the face of such influence, the curriculum was planned with little emphasis to meet the needs, concerns, and demands of Ethiopian people. The review concludes with recommendations and insight for future to improve education system in the country.
\end{abstract}

Keywords: Curriculum, Curriculum development, Education, Patterns and Trends

DOI: $10.7176 / \mathrm{HRL} / 50-01$

Publication date: November $30^{\text {th }} 2019$

\section{Introduction}

Ethiopia is one of country located in horn of Africa which has more than 100 million people today (Central Intelligence Agency, 2016). Ethiopia is also one of the frontline country for the civilization of the world. On the top of this, Ethiopia is also known for being home of different nation and nationality people living together in diversity. Ethiopia has long history in all aspects like education, cultures, norms, values, religious, farming style and so forth. This, this review work focuses on the nature and concepts of education, curriculum and curriculum development in different periods on its historical trends and patterns of education system in Ethiopia.

Thus, to materials the purpose of the review work, the author believed that it is difficult to understand the conception and practices of curriculum of a certain country without discussing the education itself. Education is a process by which a society can preserve, enrich and transmit its accumulated knowledge, skills and values in order to foster the well-being of the members of that society (TGE, 1994:9). In this context, education is considered as an instrument that can be used to bring about all rounded development of the individual and society as a whole. In addition, education is used to transform and disseminate the accepted and respected values of the society to the next generation.

In one way or another, to address all these purpose of education, it is a must to think about curriculum since education is unthinkable without curriculum. Curriculum is the central element or the main means to achieve the purposes of education. The meaning of curriculum is very illusive. To most educators curriculum is more explained than defined. According to Schubert (1986), curriculum can be defined in terms of: "(a) content or subject matter, (b) a program of planned activities, (c) intended learning outcomes, (d) cultural reproduction, (e) discrete tasks and concepts, (f) an agenda for social reconstruction, and (g) 'currere' (interpretation of lived experience)."

Once the concept of curriculum made clear, what immediately comes to one's mind is about curriculum development. Although the concept of curriculum development has been defined in different ways (see Ornstein and Hunkins, 2004); Print, 1993; ICDR, 1999), it is possible to put these variations into main approaches. Firstly, curriculum development is conceived as content selection (Ornstein and Hunkins, 2004). Secondly, curriculum development is seen as the overall planning of learning opportunities (Print, 2004). And third, curriculum development is seen as selection of contents and organizing them into learning materials (ICDR, 1999). In practice it is possible to argue that curriculum development involves all of the three approaches. It is as much a planning process as it is both content selection and the development of curriculum materials.

To this effect, in history of Ethiopian education, anyone can impart or acquire knowledge indifferent ways. Those can be through traditional education system and modern education system. In fact many scholars define 
traditional education as indigenous and religious education system. Whereas, the religious education system in Ethiopia is further classified as Church education and Quranic education (Hailegebriel, 1970).

\section{Research method}

Qualitative research method more specifically historical research design was employed to explore an overviews of Ethiopian education system with emphasis of curriculum development processes in different periods of its historical trends and patterns. Secondary data were collected from different literatures and personal experiences of the author. Collected data were coded and classified in to different themes that make sound and enable author to get answer to the research question.

\section{Data analysis}

It is difficult to understand the conception and practices of curriculum and curriculum development of a certain country without discussing the education itself. Thus, education is universally acknowledged in a vast body of literature as an essential element in the process of national development (Lockheed \&Verspoor, 1991). Education is a process by which a society can preserve, enrich and transmit its accumulated knowledge, skills and values in order to foster the well-being of the members of that society (TGE, 1994:9). In this context, it is a common standpoint that education is an instrument that can be used to bring about all rounded development of the individual and society as a whole. In addition, education is used to transform and disseminate the accepted and respected values of the society to the next generation.

Therefore, these all purposes of education can only be realized through an effective plan of education generally referred to as the curriculum of the school system (Shiundo and Omulando, 1992; Tyler, 1949; Orestein, 2004). Thus, it is possible to conclude that the process of development can be realized when the curriculum is designed in such a way that it reflects the needs and interests of the students and social forces existing in a given society or community. Perhaps this is why, some prominent educators (Tyler, 1949; Taba, 1962) in Institute of Curriculum Development and Research, ICDR (1999) strongly stress that curriculum issues are central to education and the curriculum should be at the heart of the educational enterprise.

From discussion made so far, curriculum is a central element or a means to achieve the purpose of education. To more educators curriculum is more explained than defined. In connection to these, scholars like Ornstein and Hunkins (2004), Abebe (1986), Solomon (2008) and Amareand et al., (2000) contested that curriculum is a value laden term to the extent that its definitions are closely tied to certain value systems.

Cognizant of these facts, the term curriculum is not defined and understood to have one and universally acceptable meanings upon which all educators, educational writers and people who are concerned about education agree. For example, a subject centered curriculum experts, such as Bestor (1963); Kroevisky and Learner (1984), and others argue that curriculum is defined as the sum total or collection of subject matters that promote the intellectual capacity of learners in the school. In connection with this, Tyler (1949) contributes much by synthesizing the various meanings of the curriculum. Thus, for Tyler (1949), the curriculum is a subject matter to be taught or course to be given to the students, so that learners bring the desired changes in their behaviors.

On the other hand, there are others who advocate the experience centered curriculum. The advocates of the experience centered curriculum such as Count (1963) and Ornstein and Hunkins (2004) view curriculum as everything that transpires in the process of planning and learning in an educational institution. In supporting the above ideas, Aggrawal (2004:47), defines curriculum as everything that goes within or without the school system that are relevant to the learners including extra class activities, guidance, interpersonal relationship and the like. Derebssa (2004) and Abebe (1986), define curriculum in similar ways. For instance, Derebssa (2004) defines curriculum as all of the activities engaged in by the pupils, teachers, supervisors, principals, parents, and others that are in anyways affected by study in, through and out of the school.

There are still other scholars who consider curriculum as a written plan or a plan for certain educational program. For example, Beauchamp (1982:25) believes that "a curriculum is a written plan depicting the scope and arrangement of the projected educational program for a school." For Taba (1962), the curriculum is the plan of a certain educational program. This idea is shared by Good (1973:157) in that for Good (1973) curriculum is considered as a plan for educational programs. Hence, the curriculum for the above scholar is a plan/ program with contents to qualify learners to a certain end.

Lawton (1976) sees curriculum as something that can value culture. For him, curriculum is defined as set of experiences designed to train children into the culture of their society. In other words, curriculum is essentially a selection from the culture of a society for the purpose of transmitting its important cultural traits and ethical systems. Still Chamber's Dictionary cited in Shiundu and Omulando (1992:39) trace the concept of 'curriculum' is best understood from the Latin root of the word 'Currere', meaning 'to run, more probably to run a course'. Therefore, curriculum represents a course of subjects covered by students in their 'race' towards the destination, the finish line which may be a certificate, a diploma or a degree.

To this end, having seen the definition of the curriculum from the perspectives of its wider context, an 
examination of the documents in Ethiopia reveals that: "curriculum is an educational document of the state which is to be strictly followed by all schools and which encompasses planning a predetermined purposeful course of study for particular target group of the learners (MoE, 1993:1)." The definition given for the curriculum in the Ethiopian context resembles the definition given by Tyler, which understood curriculum as the educational policy in operation at school level. Practically, it has been understood as the sum total of all subjects taught at the school (syllabus, textbooks, and teachers' guide).

Even though different scholars define curriculum in different ways from their own perspectives, however, for this review work; Tyler's definition of the curriculum is taken as a working definition. According to Tyler (1949:1), the curriculum is a subject matter to be taught or course to be given for the students, so that learners bring the desired changes in their behaviors. This conceptualization of the term goes beyond the notion of simply preparing a planned document to be applied later. When a curriculum document is implemented in an institution with an educational program (kindergarten, school, college and university), interaction takes place between the document, learners and instructors such that modification occurs and a 'curriculum' emerges (Tyler, 1949). To follow the procedures, there is a need for planning, to organize the activities and programming, which is termed as curriculum development.

After a look in to the concept of curriculum, what immediately comes to our mind is, about the concept of curriculum development. The concept of curriculum development lends itself to different interpretations. For Ornstein and Hunkins (2004), curriculum development is the process of selecting and organizing the contents of the subjects to be taught. Print (1993) defines curriculum development as the process of planning, constructing, implementing and evaluating learning opportunities intended to produce designed changes in the learners. For him, it must be seen as a deliberate, purposeful, planning activity that seeks to achieve general and specific intentions.

The more elaborated and operational meanings of the curriculum development in the context of Ethiopian educational policy as a given by MoE (1994) and ICDR (1999) in Solomon (2008:43) reads as:

"Curriculum development is a comprehensive term that includes collecting of the information, curriculum planning, developing syllabus, and other instructional materials, trying out and testing the materials improving the materials according to the result of the try-out evaluation and implementation of the curriculum."

Although the concept of curriculum development has been defined in different ways (see Ornstein and Hunkins, 2004); Print, 1993; ICDR, 1999), it is possible to put these variations into main approaches. Firstly, curriculum development is conceived as content selction (Ornstein and Hunkins, 2004). Secondly, curriculum development is seen as the overall planning of learning opportunities (Print, 2004). And third, curriculum development is seen as selection of contents and organizing them into learning materials (ICDR, 1999). In practice, it is possible to argue that curriculum development involves all of the three approaches. It is as much a planning process as it is both content selection and the development of curriculum materials.

Most curriculum experts believe that curriculum planning is based on objectives, curriculum (educational) experiences which consist of content and methods, organization and evaluation. The planning is reflected in syllabuses or in subject guidelines, teacher's guide, student's text and supplementary materials (Ornstein and Hunkins, 2004). Some say that curriculum development does not only entail the planning aspect but also tryout (pilot testing of the curriculum in few classes and modifying material), implementation at national level, and quality control.

However, a look into Ethiopian education system in general and curriculum development in particular has undergone several phase of development and where the chronological development of the system of education in Ethiopia may be debated. However, available scholarships by Tekeste Negash (1990), Teshome Wagaw (1979), Pankhurst (1974), and Woube Kassaye (2005) seem to rest on two broad historical phases: Traditional education and also called pre-modern education (pre-1908) and modern education which further classified into different period: from 1908- to $1974 ; 1974$ to 1991 ; and post-1991 to the present.

The first historical phase of education in Ethiopia was Traditional education in Ethiopia (Pre-1908), where the author argues that one cannot talk about education without traditional education. Traditional education in Ethiopia had long history which contributed a lot for today's modern education in the country (Teshome, 1979, Teksste, 1990). Traditional education in Ethiopia mainly refers to the indigenous and religious education (more specifically, the Church and Quranic education).

Indigenous education includes informal education conducted by many Ethiopians outside churches and mosques. Indigenous education is offered by all ethnic and linguistic groups and remains an important transmitter of cultural identity from one generation to the next. Learning begins very early in life, soon after birth, and continues until death. Indigenous education is, therefore, essentially a part of life of the society and the question of values in indigenous education becomes inseparable from the larger questions of values in Ethiopian life (Teshome, 1979, Teksste, 1990). That is why an author is claiming that traditional education is not only the one that takes place under the control of religious education. In Ethiopian context, indigenous education was there before the introduction of religious education in Ethiopia. This implies that there was another path of acquiring 
knowledge out of the so called Ethiopian traditional education which an author call it indigenous education and sometimes called cultural education.

Religious education is another type of traditional education. The Ethiopian Orthodox Church was a strong indigenous institution to exercise immense influence on the country's everyday life. Having had a virtual monopoly over education in the country, it had to oppose strongly the establishment of secular education in the country. Traditional education was not confined to the Church's alone. Quranic education was also practiced in the country where Muslims live. The strength of the Orthodox Christianity and to a lesser extent of Islam, limited the impact of European missionaries in Ethiopia. Particularly, missionaries did not have positive appeal to the leaders of the Ethiopian Orthodox church; and were not received among the larger public as it was conceived primarily to convert students to their religions (Hailegabriel, 1976). According to Hailegebriel, missionaries were far less successful in Ethiopia than in many parts of Africa. Though missionary education had relatively limited roles in imparting traditional education, they were instrumental to inspire the introduction of modern education into the country.

As mentioned by author, in historical background of Ethiopian traditional education, we can observe that more focus was given to religious dogma. In traditional education, Bible / Quran were considered as an ultimate source of knowledge, whereas, teachers are transmitter of this reality. The role of teachers is to nurture the spiritual growth of their students, to bring latent knowledge and ideas to consciousness and to be a moral and spiritual leader. A religious education gave attention to a subject centered that emphasis truths gained from enduring theological, philosophical, historical, literary, and artistic works in the Bible / Quran and engineering, poem, craftsman, and leadership. In traditional education of religious education all learning experiences and the content were predetermined by the church or mosque literates of religious leaders and teachers. Subject to be learned was arranged accordingly based on their complexity level. At the first stage they taught alphabet, next reading and writing then at the end religious dogma will be offered to the students.

In general, in traditional education there were no formal written documents of education like today. There was no do's and do not do's. The way contents organized was not as such on the line of educational theories. They were simply training their descendant's mind and hand through participatory way of learning. During this time student engaged in the activity posed to them and made adaptation. This adaptation was built through process and over time.

The second historical phase of education in Ethiopia was the period of modern education (Post- 1908). The period of modern education in Ethiopia (post -1908), according to Tekeste (1990), Teshome (1979), Pankhurst (1974), and Woube (2005) can be classified into different periods: from 1908 to 1974; 1974 to 1991; and post1991 to the present.

The first period of modern education was from 1908-1974. This period was characterized by the formal introduction of modern or secular education into the country by the government at the turn of the twentieth century, during the reign of emperor Minilik II. It is widely held that Minilik II had a very tough time trying to convince the general public as well as members of the clergy and the aristocracy as to the benefits of modern education for the development of the country (Seyoum, 1986).

Minilik II opened the first state supported educational institution: Minilik II School in his palace compound for the sons of the nobility and dignitaries in Addis Ababa in 1908 (Seyoum, 1986). The aim of the introduction of modern education by Menelik II was both for the modernization of the country and to cope up with international political context (Tekeste 1990). Furthermore, the curriculum of the government schools started by Emperor Minilik II was intended to supplement, not to replace, the traditional instructions given in the church schools. The school was designed to provide a selected group of students with linguistic and other skills necessary to enable Ethiopia to maintain satisfactory relations with other countries. Nonetheless, as stated in Woube (2005), there was no standard policy regarding curricula, textbook and language of instruction. Mainly the curriculum during this period was dominated bythe study of languages like French, English, Italian and Arabic. The curriculum during this perod was known as French oriented curriculum.

Some years the death of Menelik II, Emperor Hailesellassie (1930-1974) came to power first as a Regent and an heir to the throne. Teshome (1979), Tekeste (1990), and Woube (2002) noted that the Emperor had enthusiasm to expand education and opened a school after his own name, Teferi Mekonnen School, as demonstration of his commitment. The school structure during the Haileselassie time was a six-year primary, six-year secondary, and four-years of university education programs, with special emphasis on teacher-training and agriculture.

Regarding the progress made on Ethiopian education, Woube (2005) discusses some significant developments in the education sector took place before and after the 1936-41, Italian occupation of Ethiopia. According to Woube, the Italian occupation disrupted all efforts made in expanding modern educational activities. The invasion of Ethiopia by Italy in 1936 resulted in the closing of the government school system started by Emperor Minilik II and greatly expanded under Emperor Haileselasse. Under the Italian aggression schools were only closed down, but also changed into barracks and hospitals. The Italians changed the official language of the country to Italian and employed a multilingual education, as per the Fascist's "edict of 1936", a directive which empowers Italian regional rulers to implement indigenous languages for their subjects in Africa. Some major 
languages (e.g., Afaan Oromoo, Tigrigna, Somali, Harari and Kafficho came to serve as a school media in addition to Amharic (Tekeste, 1990). The curriculum during this period was known by Italian oriented curriculum.

Following the restoration of the country's independence from the Italian rule in 1942, a lot of efforts were made to recover, the educational system. However, the government faced a great shortage of funds as the result of which it decided the British government for assistance and to make available materials and personal resources (Teshome, 1979). Thereafter, most of the schools after the war were directed by British personnel. After the Second World War, the Monarchical Government adopted English as a second language for its bureaucracy and as a language of instruction in schools. Since that time, English has been introduced as a subject in primary and medium of instructionin secondary and higher education (Ministry of Education, 1994).

The second period of modern education was Education at the Derg Regime (1974-1991). After the downfall of the then Emperor Hailesellasse, the Military Regime took over power in 1974. Last (1980) states that during the Military Regime, the educational system was organized along a new set of principles. The primary aim of the regime was to expand educational services in the rural areas and more importantly to propagate socialist ideology. The educational policy of the military government had six years of primary, two years of junior secondary, four years of secondary and four years of tertiary education. At that time, there were several literacy campaign programs which led many Ethiopians to become literate. The rate of illiteracy was reported to have been quantitatively minimized from about $93 \%$ in 1979 to $37 \%$ in 1983 (MoE, 1996). The military education system was, however, criticized for emphasizing quantity in measuring progress in the educational sector, and for paying little attention to the quality of education (Tekste, 2006). The types of curriculum used during Derge period was Russian oriented curriculum.

The third period of modern education is the Current Education System from 1991 onwards). In 1991, the Derg Regime was overthrown, and then replaced by transitional Government of Ethiopia. The transitional Government of Ethiopia made various changes, including a change in the policy of the country's educational system that led to the education and Training Policy of Ethiopia (ETP) in 1994. This policy is generally claimed to be qualitatively different from the old education system because of the changes that were introduced in the school structure. It established eight years of primary education, with the first cycle for grades 1-4, and the second cycle for grades 5-8. Similarily, the secondary education has also two cycles: first cycle for grades 9-10 and the second cycle grades 11-12. The first cycle secondary education prepares students for academic programs and for enrolment in vocational education. The seconday cycle prepares students to choose subjects leading for higher education. (TGE, 1994).

The Education Sector Development Program (ESDP) is designed to implement the Education Training Policy with the main focus on educational quality; relevance, equity and access to schools with special emphasis to the rural and a marginalized areas, improving girls' education and with a target to achieve Universal Primary Education (UPE) in 2015 (MoE, 1998). The program was launched in 1997 and has a twenty-year life span divided into four phases of implementation. Regions have been made to design their own ESDPs according to specific regional educational needs and guidelines of the Federal Ministry of Education (ibid).The program encompasses all levels of education and demanded significant amount of educational resources; more than what was possible from the existing economy. Consequently, its implementation required participation and contribution of internal and external stakeholder including communities and international donor agencies. There has been encouraging progress in educational development in Ethiopia since the launching of ESDP (Chali, 2010; MoE, 1998, 2002, 2005). The ESDP has given more emphasis to expansion of schools in the rural areas and the periphery. Enrollments of girls at primary and secondary levels have increased, especially in primary schools (MoE, 2005). In spite of these achievements, the education system still suffers from many problems (Chali, 2010; MoE, 2005). There is a large disparity in educational achievement among regions, between urban and rural areas, and between males and females. Internal inefficiency and dropout rate are still high problems (Chali, 2010; MoE, 2005).

Unlike the previous government, the post 1991, the government embarked on a decentralization policy to legitimize the new state and empower the citizens and/or country's ethnic groups located by regions; and devolve power to the local level following the 1992 constitution of the transitional government of Ethiopia (GebreEgziabher, 2007). It was intended to open the way for regional and local governments and through them for local communities, to take greater responsibility, financial and otherwise, for managing their own affairs, including the delivery of social services (Dufera, 2005).

In addition to this, the Education and Training Policy emphasized that every nation and nationality has the right to use its own language as a medium of instruction at the primary level depending on their own decisions. For the first time in the history of Ethiopia, indigenous languages other than the Amharic language have been incorporated in the school curriculum. This means that every child has the right to learn primary education through his/her mother tongue. Currently, primary education is being provided in the ethnic languages (MoE, 2002). In addition to this, as indicated in Jeilu (2006), the Ethiopian government has pursued a decentralization policy by shifting authority and responsibility to the regional states since, 1992. The decentralization reforms as well as the education and training policy (TGE, 1994); seek to improve access, equity, quality, relevance and efficiency of 
the education system.

In his further explanation about the development of the primary education curriculum, Jeilu (2006: 81) wrote: The decision in the area of curriculum and instruction was made at the regional levels and national levels. The practice showed that the setting of the curriculum framework for the primary education is the responsibility of the ministry of education. In practice the syllabus for almost all subjects, with the exception of the nationality languages were drafted at national level and then developed jointly with the views of keeping the uniformity and standards.

Furthermore, the responsibility of developing the flowcharts and the syllabus was given to ICDR (Woube, 2005). After syllabi are developed and approved by the ICDR, the preparation of textbook for primary school (18 ) is the responsibility of the regions. It is expected that, this decentralization policy will have a positive contribution in keeping the balance and relevance of the curriculum of each region. It was also decided by the policy that Amharic has become a language of nationwide communication in government offices and is taught as a subject since grade 3 except in the Amhara region. English is taught as a subject starting from grade one and is the medium of instruction for secondary and higher education.

In conclusion, it can be said that the present education and training policy has won the support and mobilization of a robust community initiative for at least two main reasons: the decentralized educational management and the use of regional/local languages for the primary level education. If government and communities' commitments continue with current momentum, the education and training programs in the country will bring about desired changes in the sector, of course, notwithstanding the critical attention to be squarely paid to the quality challenges at all levels.

\section{Conclusions}

Ethiopia is one of the country located in horn of Africa which has more than 100 million people today. Ethiopia is also one of the frontline country for the civilization of the world. On the top of this, Ethiopia is also known for being home of different nation and nationality people living together in diversity. Ethiopia has long history in all aspects like education, cultures, norms, values, religious, farming style and so forth.

Education system in Ethiopia has two parts. The traditional education system and modern education system. The traditional education system mainly refers to the indigenous education system, which got negligible emphasis in the history of traditional education and the religious education system. In Ethiopian context, religious education system mainly refers to the Church education and Quranic education. And these institutions have been offering various lesson for the centuries. However, theses traditional education have never got the attention it deserves from scholars.

When it comes to the modern or western education system Ethiopia's, the modern education system has passed through different chapters or phases each of which has its own characteristic feature. By and large, despite these problems, the initiatives taken to introduce modern education in the country is commendable.

However, there were still serious shortcomings. The curriculum was highly dominated by contents borrowed from the experience of other countries. Besides, students suffered from language difficulty, there was shortage of qualified teachers and curriculum experts, and there was no attempt to revise the curriculum that reflect the needs and interests Ethiopian people.

As of introduction of modern education to down fall of Derge period, 1991, the education system of Ethiopia in general and the curriculum in particular has undergone several phases of development with subsequent foreign influence. In the face of such influence, the curriculum was planned with little emphasis to meet the needs, concerns, and demands of Ethiopian people.

However, as of post-1991 period, education system in our country, Ethiopia has brought about drastic changes on the curriculum. Decentralization of education and change of medium of instruction were some of the changes. Textbooks were translated to fit the new needs. New curriculum was prepared for different levels of education. However, most of the made hastily. As a result, teachers were not sufficiently oriented. There were shortages of textbooks.

Generally speaking, the understanding and practice of curriculum development in Ethiopia at different period varied greatly. Although there were few good practices of curriculum development, by and large it has encountered several problems. Their emphasis given to Ethiopianize the curriculum has been little. Public and professional engagement in curriculum development is little or totally missed in most phases of modern education.

\section{Recommendations and insight into the future}

It is universally agreed that development of any country is largely dependent on an educated workforce (Hoot, Szente \& Tadesse, 2006). Fortunately, the Ethiopian government understands the value of education and currently dedicates a significant amount of resources towards its development at all levels recognizing the need for $21^{\text {st }}$ century workers who are skilled in science, technology, and mathematics. The following 
recommendations are thus offered to help Ethiopia develop its most precious resource, the Ethiopian people, in a sustainable way to enhance the quality of life and economic prosperity for all.

$\checkmark$ First, it is understood that the history of foreign involvement in Ethiopia's history, particularly in the area of education - where curricular decisions, selection of instructional languages, and cultural considerations - have shaped the evolution of education in Ethiopia. It is therefore recommended those who are developing the educational system are strongly encouraged to focus primarily on meeting the needs of the Ethiopian people, with the knowledge and skills necessary to be successful, not only in the cultural and political context of the country and to prepare Ethiopians to be world citizens, skilled at operating in a global marketplace of commerce and ideas. Consequently, the educational system of Ethiopia must simultaneously be culturally relevant and flexible/responsive.

$\checkmark$ Second, gender equity must also be reflected in Ethiopia ${ }^{e e}$ s educational system. The concept of inclusive education is broad and encompassing not just physical inclusion, but also the active participation of all learners. Thus, the mere presence of girls in schools is necessary but insufficient. For gender equality, the curriculum and instruction in Ethiopia must engage all learners, as the system should prepare boys and girls to meet the country's economic and social needs.

$\checkmark \quad$ Third, currently the educational system is criticized of quality. Though there are many factors for the decline, lack of conducive environment in general and large classroom in particular plays a pivotal role. This is because collaborative work and the notion of active learning that the policy dictates are unthinkable in such situations.

$\checkmark$ Lastly, due to the country's economic level it is clear that, Ethiopian students hope learning to over through their poverty and then help their poor parents. But, unemployment makes the graduates hopeless and initiates them to migrate, seeking a promising work in other countries which leads to brain drain. Thus, learning must lead to immediate value hence unemployment should be resolved. Find job opportunity outside the country officially as of many other countries if all jobs are assumed to be saturated inside the country through. Another solution might be producing flexible curriculum that serves the needs of all students that helps develop the higher-level skills, by including native language as a medium of instruction at all levels of education.

\section{Refrences}

Abebe, Bekele (1986). "Insights into the Concepts of the curriculum," The Ethiopian Journal of Education.10 (1) Aggrawal, J.C. (1996). Teacher and Education in a Developing Society (4th ed). New Delhi: Vikas publishing house $\mathrm{pVt}$ Ltd

Amare, Asgedom and et al. (2000). "A Framework for the Curriculum Design in Higher Education," Journal of the education. Addis Ababa: IER Flambeau

Beauchamp, George A. (1982). Curriculum theory: planning, development and use. "Theory in to practice." Vol.39. No.1. pp.23

Chali, N. (2010). Oromiyaa Today: A pocket guide 2008/09. Finfinnee, Ethiopia: Oromia National Regional Government.

Cenetral Intellegency Agency, CIA World factbook (2016). Ethiopia demographics profile, 2016: www.indexmundi.com/Ethiopia/demographics-profile.html

Derebssa, Dufera (2004). Principles of Curriculum Development. Addis Ababa: Institute of Educational Research, IER.

Dufera, D. (2005). Prospects, challenges and policy options of Ethiopian education towards the achievement of EFA goals. Retrieved April 24, 2008, from http://home.hiroshimau.ac.jp/cice/e-forum/paper67.pdf

Gebre-Egziabher, T. \& Berhanu, K. (2007). A literature review of decentralization in Ethiopia. In T.Assefa \& T. Gebre-Egziabher. (Eds.), Decentralization in Ethiopia. Addis Ababa, Ethiopia.

Good, V. Carter (1973). Dictionary of education. New York: McGraw-Hill Book Campany.

Haile Gabriel Dagne (1976). Non-government schools, in M.L. et al. (eds.), Language in Ethiopia. London: Oxford University Press

Hoot, J. Szente, J., \& Tadesse, S. (2006). "Early Childhood Teacher Education in Ethiopia: Progress and Emerging Challenges." Journal of Early Childhood Teacher Education, 27, 185-193.

ICDR (1999). Teachers Education Handbook. Addis Ababa: ICDR (Unpublished).

Jeilu, Oumer (2006). "Educational Policy and Decentralized Decision Making for Schools in Ethiopia: The Case of Oromia and Addis Ababa," Journals of Education for Development. 1(1) pp.81-105

Last, G.C. (1980). Education in socialist Ethiopia: Origins, reorientation strategy for future development. Ministry of Education (Mimeo)

Lawton, D. (1976). Class, Culture and Curriculum. London: Routled geandkegan Paul

Lockheed, M. E. and Verspoor, A.M. (1991). Improving Primary Education in Developing Countries. Washington, D.C.: Oxford University Press. 
MoE (2005). Education Sector Development Program III Program action plan. Addis Ababa, Ethiopia: Ethiopia: Ethiopian Federal Ministry of Education.

MoE (2002). Education Sector Development Program II program action plan. Addis Ababa, Ethiopia: Ethiopian Federal Ministry of Education.

MoE (1998). Education Sector Development Program I program action plan. Addis Ababa, Ethiopia: Ethiopian Federal Ministry of Education.

MoE (1996). Education sector development program. Addis Ababa: EMPDA.

MoE (1994). New education and training Policy. Addis Ababa, Ethiopia: Ethiopian Federal Ministry of Education.

MoE (1993). Ethiopian Educational Policy Implementation Strategies. Addis Ababa, Ethiopia: Ethiopian Federal Ministry of Education (unpublished).

Ornstein, A. C. and Hunkins (2004). Curriculum, Foundations, Principles, and Issues (4th ed.) New York: Pearson Education, Inc.

Pankhurst, R. (1974). "Education, language and history: An historical background to post-war Ethiopia," The Ethiopian Journal of Education. Vii (1); 75-97.

Print, M. (1993). Curriculum Development and Design. Sydney: Allen and Unwin.

Seyoum, Tefera. (1986). "The education of women in Ethiopia: A missing piece in the development puzzle", The Ethiopian Journal of Education. AAU, IER. VX, N 1.

Shiundu, J. S. and Omulando, S.J. (1992). Curriculum: Theory and Practice in Kenya. Nairobi: Oxford

Solomon, Areaya (2008). Policy Formulation Curriculum Development and Implementation in Ethiopia. Addis Ababa University: Addis Ababa Book Centre.

Taba, H. (1962). Curriculum Development: New York: Harcourt, Brace and World. Inc.

Tekelhaymanot, Hailesillasie (2001). The cultural foundation of of Education in Ethiopia. 9-16. Hamburg: VerlagDr.Kovac.

Tekste Negash. (2006). Education in Ethiopia: From crises to collapse. Uppsala, Sweden: Nordiska Afrikainstitutet.

Tekste, Negash (1990). The Crisis of Ethiopian Education: Some Implications for the Nation Building. Uppsala: Uppsala, University of Wisconsin.

Teshome, Wagaw (1979). Education in Ethiopia: prospect and retrospect. Annaibor: The university of Michigan press

TGE (1994). Education and Training Policy. Addis Ababa: EMPDA

Tyler, R.W (1949). Basic Principles of Curriculum and Instruction. Chicago: University of Chicago Press.

Woube, Kassay (2005). "An Overview of the Curriculum Development in Ethiopia: 1908-2005," Educational Journals of the Social Science and Humanities. 3 (1). Addis Ababa: Addis Ababa University press. 